\title{
STRATEGIES TO CONFRONT URBAN ENCROACHMENT IN LIGHT OF THE THEORY OF (BROKEN WINDOW) (INFRASTRUCTURE SERVICES FOR THE HOLY CITY OF NAJAF, A CASE STUDY)
}

\author{
Arkan A. Al-Nasrawy ${ }^{1}$ and Evian N. Al-Laban ${ }^{2}$ \\ ${ }^{1}$ Phd. Philosophy In Urban And Regional Planning, Lecturer, Faculty of Physical \\ Planning, Kufa University, Iraq. Email: arkaan.manji@uokufa.edu.iq \\ ${ }^{2}$ Diploma in urban planning, Civil Engineering, Najaf Water Directorate (NWD), Iraq. \\ Email: eng.evian.nassim@gmail.com
}

\section{HTTP://DX.DOI.ORG/10.30572/2018/KJE/120206}

\begin{abstract}
The aim of this paper is to study the definition of (infringement) and its effects on human beings and their activities and knowledge of the reasons for the infringement on infrastructure services in the study area in order to come up with solutions and proposals that achieve cost, effort and time savings since the work was based on the descriptive and analytical approach by diagnosing the characteristics and indications of the breaking windows theory and the most important scientific experiments. That it included identifying indicators of the urban encroachment phenomenon to build the necessary strategies within the study area to address the research problem.
\end{abstract}

KEYWORDS: Broken windows theory; urban infringement; infrastructures; urban structure. 


\section{INTRODUCTION}

The most prominent way to test the phenomenon of urban encroachment is to apply the theory of broken windows, which states that a person possesses the ability, capacity, love of discipline, and adherence to laws and public morals when he finds an environment that encourages that, but quickly releases from this commitment when it sees the chaos around it and that the theory of the broken window clarifies We have that every problem, whether small or large, is left unresolved in a particular environment that greatly affects people's attitude towards that environment and leads to the emergence of more problems. The theory is a societal theory that relates to society in all its economic, cultural, legal, security, and subjective aspects in a direct way, and here lies its importance for its use in Examining the phenomenon of urban encroachment as the phenomenon is a societal phenomenon, testing and treating it requires knowledge of all aspects to come up with complete and appropriate solutions

\subsection{Research problem}

What are the factors and indicators of urban encroachment on infrastructure services in the study area in light of the implications of the theory of broken windows (BROKEN WINDOWS)?

\subsection{Research Objective}

The aim of the research is to: -

1-Defining the concept of (infringement) and its impact on human beings and their activities, knowing the reasons for the infringement of infrastructure services in the area of study and studying laws and laws relating to the treatment of this phenomenon;

2-Conducting an applied analysis to determine the factors influencing the infrastructure systems in the field of research by using the principle of broken windows in coping with the violations received.

3-To come up with solutions and proposals which allow the competent authorities to implement them in the administration, planning and monitoring of infrastructure services, provided that such solutions achieve cost, effort and time savings.

\subsection{Research theory}

The implications of the broken windows theory offer a rationale for the evaluation and treatment of the phenomenon of urban encroachment on infrastructure facilities, and it leads to the implementation of planning policy in the study area to counter this phenomenon. 


\subsection{Research Methodology}

The research is based on a descriptive and analytical approach by diagnosing the characteristics and connotations of the broken windows theory and the most important scientific experiments are included in order to determine indicators of the urban encroachment phenomenon, in particular on infrastructure services; And evaluate the phenomenon indicators using the on-site questionnaire and the methods and planning methods used to establish the appropriate strategies for solving the research issue within the study field.

\subsection{Field of study}

The study's spatial framework was calculated for the holy city of Najaf within the master plan.

\section{THEORETICAL AND CONCEPTUAL FRAMEWORK}

\subsection{Concept Theory of Broken Windows (B.W)}

The theory of the broken window is developed by criminology theorists ((James Wilson and George Keeling)) in 1982, as it states according to their dream ((that the great starts with the small, or that the big fire originates from the smallest sparks, or the small one is the beginning of its greatness)), which is the term Common to chaos and confusion within a community defined window (Zimbardo, 1973).

1-Experience of Zimbardo: This experiment was introduced in 1969 by the social scientist Philip Zimbardo in New York City, USA, where he identified two areas contrary to the economic level of the region. Zimbardo concluded that ((societal conduct) When he believes that the element has been abandoned What does not matter to anyone about his fate may lead to actions that may clash with the convictions of those who carry it out, which may amount to crimes, neglect or indifference as to what is happening with that element) (Zimbardo, 1973).

2-the experiment with the New York City transportation system: The idea with broken windows theory was used by (Mr. David Bratton) to discuss the transportation system crisis in New York City in the United States in 1990; Where he carried out a series of legal and administrative procedures in an effort to solve the problems of The beginning before it escalated and progressed and as a result of those decisions he achieved with great success and as a result, the theory was implemented in the different the United States (Harcourt, 1998).

The most important indicators derived from the international experiences of the broken windows theory 
A set of indicators were deduced from the above through international experiments which tested the theory of broken windows (B.W), and a table is explained as follows (Table 1):

Table 1. The most important indicators derived from the broken windows theory, source: the researcher based on prior experiences.

\begin{tabular}{ll}
\hline \multicolumn{2}{c}{ Indication } \\
\hline 1 & $\begin{array}{l}\text { A society's deliberate sabotage results in social differences (turmoil, panic, } \\
\text { withdrawal). }\end{array}$ \\
\hline 2 & $\begin{array}{l}\text { One of the major causes of crime and social instability is a deterioration in respect of } \\
\text { people's laws, properties, and freedoms. }\end{array}$ \\
\hline 3 & $\begin{array}{l}\text { The human psyche tends to be disturbed and dysfunctional as it sees the social turmoil } \\
\text { and lack of responsibility. }\end{array}$ \\
\hline 4 & Ignoring the little problems in the future will lead to bigger and bigger problems. \\
\hline 5 & $\begin{array}{l}\text { That societal values play a major role in giving supreme value to the public order and } \\
\text { to the sense of belonging and security of individuals when there are participants who } \\
\text { contribute to supporting and maintaining the system }\end{array}$ \\
\hline 6 & $\begin{array}{l}\text { Crime levels (high or low) have little effect on society's distribution of disorder, } \\
\text { confusion and interference. }\end{array}$ \\
\hline
\end{tabular}

\section{The influence of broken windows theory experiments}

Through our study of the concept of the theory of broken windows and the most important concepts that clarified its meaning, and studies that dealt with its interpretation and experiments that were tested to clarify the extent of its impact on society and its usefulness in community reform, it was noted that the theory differs according to the affected factors, so we noticed that it has a very big impact when applied to Community level. And societal relations, represented mainly by the family and the individual, arose in addition to the second basic environment school in the life of the individual and in terms of maintaining security by the concerned authorities and the importance of laws and legislations stipulated for their protection of facilities, the punishment of aggressors, and a sense of stability in light of the tyranny of security and the fair and strict application of law embodied in it Justice and respect in front of the community, while we see its moderate influence. On the cultural, educational and economic level of the society, the difference of cultures, nor the educational level, does not constitute a major and fundamental effect that pushes the community to practice encroachment on facilities and property, while we noticed a weak effect when it was tested for purposes related to awareness and a sense of the community's belonging to the surrounding urban structure, stability and interest in it services as the mind of institutions providing service This is why the theory was able to bring about an important and positive change in societal factors, law and security, which reduced and eliminated the violation. On the other hand, no noticeable changes 
occurred in the individual in particular and in the economic factor. Broken windows according to the following factors (Table 2).

Table 2. The degree of influence of the experiments of the broken windows theory on various factors/ Source: The researcher based on the above data.

\begin{tabular}{cccccc}
\hline Factors & $\begin{array}{c}\text { Self- } \\
\text { factor }\end{array}$ & $\begin{array}{c}\text { The cultural and } \\
\text { educational factor }\end{array}$ & $\begin{array}{c}\text { The economic } \\
\text { factor }\end{array}$ & $\begin{array}{c}\text { Community } \\
\text { factor }\end{array}$ & $\begin{array}{c}\text { The legal and } \\
\text { security factor }\end{array}$ \\
\hline $\begin{array}{l}\text { The degree } \\
\text { of impact }\end{array}$ & $*$ & $* *$ & $* * *$ & $* * *$ \\
$\checkmark$ & & & & \\
\hline & & &
\end{tabular}

\subsection{The concept of urban encroachment}

It applies to anything that is done by persons, organizations, and official and unofficial bodies of deliberate and accidental disruption or distortion of the urban city system, its components and materials, resulting in harm, degradation, and service provision deficiency (Mansi, 2007).

\subsubsection{General causes of urban encroachment}

The most important causes of urban encroachment are as follows (Al-Falahi, 2008):

1- Economic reasons

2- Media reasons

3- Cultural reasons

4- Societal reasons

5- Political and security reasons

6- Legal reasons

\subsubsection{Global experiences to confront urban encroachment}

1- The Brazilian Experience (The Housing and Building Research Center, 2000): The methodology followed in the development of slum areas in the Brazilian city of Rhodi Genero was aimed at

* The upgrading of informal settlements through the application of the system of tenure and ownership.

Providing necessary infrastructure services and eliminating cases of infringement according to planning criteria.

The exploitation of vacant lands to provide infrastructure and services.

Thus, this experiment succeeded in the development and development process and was adopted in other informal areas. 
2. The German Experience (Al-Sarafandi, 2001): The "Loizn Stade" project in the "Krotasberg" district in Germany was developed from successful development projects for the developed world, as the project was not interested in developing residential buildings only in the neighborhood, but also extended. To include the physical, social, economic and environmental development aspects as well as the project has achieved a goal. An important social group is the participation of the population in the various stages of the project, starting with developing proposals, and this helps to change some negative and abnormal behaviors, make decisions and implement the various elements.

\section{Synopsis of global experiments to tackle the urban encroachment phenomenon}

A table showing the most prominent international experiences led to confront the urban encroachment phenomenon as follows (Table 3).

Table 3. The most prominent of what came with global experiences to confront infringement/source: reliance on the researcher's global experience of the infringement phenomenon.

The main lessons learned from the experiences

1 Adopting the idea of developing old, slum and degraded areas to address the phenomenon of urban sprawl.

2 Ensuring the preservation of the existing societal entity in these areas and the dominant identity in the region. The change includes progress, not erasure and change of identity.

3 Improving the state of the urban infrastructure, which includes residential buildings, public and basic services and facilities.

4 Improving economic conditions, increasing the income level of the population, and providing new places and job opportunities for the population.

$5 \quad$ Residents and business owners in work areas agree on all proposals and objectives of development programs as an attempt to involve residents in decision-making to increase their sense of belonging, citizenship and responsibility towards the urban structure and infrastructure. The services it contains.

$6 \quad$ Utilizing the residential space and benefiting from it.

7 Development of public services, roads, squares, open spaces and green spaces.

8 Development and upgrading not only including the region but also exceeding the surrounding areas to integrate the population with the external environment.

9 The plan was modern and included all economic, cultural, social, urban and environmental aspects.

10 The treatment process was gradual, as it was initially adopted to improve what is there, and then moved to promotion and development.

11 Making changes and improvements in line with development, growth and future changes. 


\subsection{Interpretation of urban trespassing indicators in the light of the theory}

Through our analysis of the concept of urban encroachment and the most important explanations for urban encroachment and our analysis of the most important demonstration and its manifestations in different fields, many conclusions were drawn that were related to our previous study of the concept of the theory of broken windows, as shown in the schedule (Table 4).

Table 4. Interpretation of urban trespassing indicators in the light of the theory / source of broken windows: the researcher focused on previous theory and phenomenon data.

\begin{tabular}{|c|c|}
\hline & Indication \\
\hline 1 & $\begin{array}{l}\text { There are many economic causes that led to the phenomenon of urban encroachment, } \\
\text { represented by the imbalance of living, services, villas, job opportunities, } \\
\text { unemployment, and poverty between the countryside and the city, which leads to } \\
\text { migration and increased pressure on the urban structure of the city. }\end{array}$ \\
\hline 2 & $\begin{array}{l}\text { There are many social causes that led to the phenomenon of urban encroachment, } \\
\text { represented by the lack of the necessary needs of the community in terms of housing, } \\
\text { services and facilities, which generates pressure on the psyche of society and a feeling } \\
\text { of injustice and injustice, which creates hostility. }\end{array}$ \\
\hline 3 & $\begin{array}{l}\text { There are many cultural reasons that led to the phenomenon of urban encroachment, } \\
\text { represented by the lack of awareness, culture and lack of knowledge of planners and } \\
\text { designers in addition to the lack of culture in the knowledge of laws and their application. }\end{array}$ \\
\hline 4 & $\begin{array}{l}\text { The manifestations of encroachment differ from one region to another within the urban } \\
\text { fabric according to several societal, economic, security and cultural factors for each } \\
\text { region or fabric. }\end{array}$ \\
\hline 5 & $\begin{array}{l}\text { It is possible to control the phenomenon of infringement and disorder at the beginning } \\
\text { of its occurrence before it turns into a problem that cannot be controlled. }\end{array}$ \\
\hline 6 & Every urban structure has its own human, economic and community nature \\
\hline 7 & $\begin{array}{l}\text { There is a direct relationship between achieving the goals of the broken window theory } \\
\text { and limiting the phenomenon of infringement. }\end{array}$ \\
\hline 8 & $\begin{array}{l}\text { Lack of awareness and sense of responsibility towards services and events in the urban } \\
\text { structure. }\end{array}$ \\
\hline 9 & $\begin{array}{l}\text { The occurrence of urban encroachment is not related to a person's ability or inability to } \\
\text { actually do it, but rather to the circumstances that allow and push him to do an act. }\end{array}$ \\
\hline
\end{tabular}

\subsection{The relationship between measures of the urban encroachment phenomenon and the achievement of the goals of the broken windows theory}

From the above, the relationship between the urban encroachment phenomenon and the connotations of the theory of broken windows has been extracted and, as shown in the (Fig. 1), the implementation of the theory in an area has a direct influence on certain aspects and the most important problems resulting from the absence of these aspects and the indirect effect on other aspects and the most significant problems. 


\subsubsection{Infrastructure Services concept}

It is defined as the main infrastructure or infrastructure located beneath the earth's surface, and it is also called upon to provide all the important services, facilities and amenities vital to society (such as water, electricity, highways, railways, communications, mail and sewage) (Al-Maliki, 2013). From the above, it can be concluded that the infrastructure services are represented by a group of facilities and buildings (whether underground or on the ground) that if they are secured and guaranteed to operate with high performance, they will be expressed positively in the reality of the city, and if there are any flaws and failures therein, they will reflect negatively on the city. The elements of infrastructure services work incompletely and in an orderly manner in terms of coherence and integration, for example when there is an organized and highly efficient road network that has helped to facilitate health and education services, and when the electricity system works with full productivity and capacity, it helps to ensure the work of the rest of the services (whether drinking water or Sanitation and others).

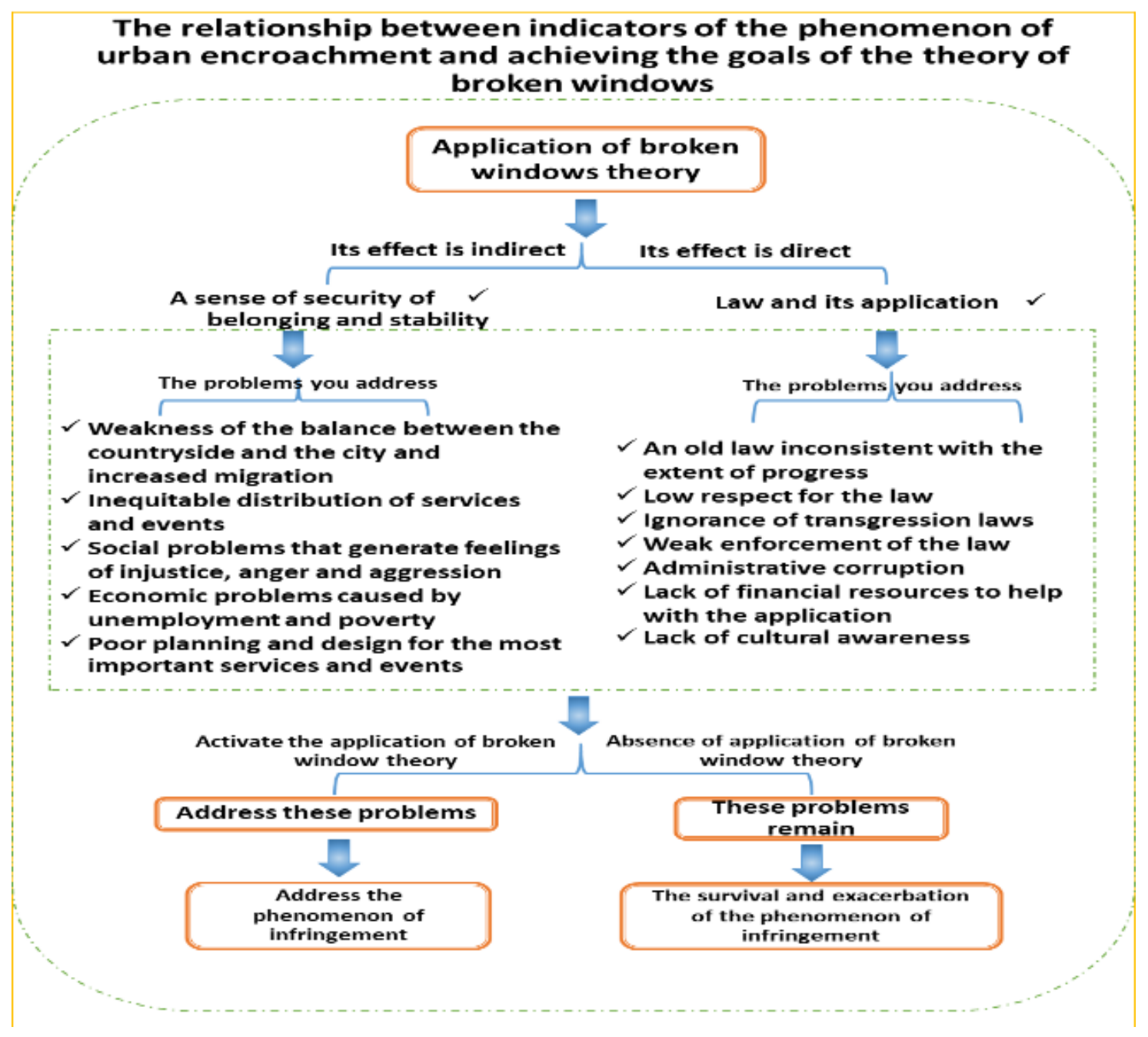

Fig. 1. The relationship between indicators of the phenomenon of urban encroachment / source: the researcher based on previous data 


\subsubsection{Drinking-Water services}

The physicochemical method is one of the popular methods of drinking water treatment, and there are several other methods. Drinking water treatment is of tremendous environmental significance when it comes to protecting the atmosphere and people alike, and drinking water comes in today after it goes through stages through filters and contains chemicals. To disinfect it, sterilize and eliminate impurities and bacteria and make it safe for human use, filters are used mainly for the disposal and separation of organic bodies and toxic and suspended minerals, while chlorine is used to sterilize water from germs and parasites. The purpose of these methods is to purify water according to specifications which differ from country to country (Omar, 2010).

\subsubsection{Drinking-water distribution systems (Table 5)}

Table 5. Summary of the types of drinking water delivery system / Source: The researcher based on the above data.

\begin{tabular}{|c|c|c|c|c|}
\hline $\mathrm{V}$ & Notes & Negatives & Positives & System type \\
\hline 1 & & $\begin{array}{l}\text { The large number of ends } \\
\text { lead to depriving many } \\
\text { areas of water during the } \\
\text { maintenance process due } \\
\text { to the closing of the lines }\end{array}$ & $\begin{array}{l}\text { 1- The lowest cost } \\
\text { among other types } \\
\text { This method of distribution } \\
\text { is applied in human } \\
\text { gatherings that are far apart } \\
\text { and scattered among them, } \\
\text { and which is difficult to } \\
\text { connect between parts of the } \\
\text { city in an integrated manner } \\
\text { due to the complex } \\
\text { topographical and terrain } \\
\text { situation of the region }\end{array}$ & $\begin{array}{lr}\text { Tree } & \text { branching } \\
\text { system } & \text { with } \\
\text { closed or dead } \\
\text { ends }\end{array}$ \\
\hline 2 & $\begin{array}{l}\text { It is preferred } \\
\text { to be used in } \\
\text { cities that are } \\
\text { expanding } \\
\text { and growing } \\
\text { in a circular } \\
\text { way }\end{array}$ & $\begin{array}{l}\text { Limited use } \\
\text { only in cities that are } \\
\text { expanding and growing } \\
\text { around) }\end{array}$ & $\begin{array}{l}\text { 1- Water maintains high } \\
\text { drainage and pressure until it } \\
\text { starts to be distributed }\end{array}$ & Circular system \\
\hline 3 & $\begin{array}{l}\begin{array}{l}\text { The best } \\
\text { types of } \\
\text { systems (for } \\
\text { water } \\
\text { pressure in } \\
\text { the pipes) }\end{array}\end{array}$ & & $\begin{array}{l}\text { It delivers water to any point } \\
\text { from more than one way }\end{array}$ & $\begin{array}{l}\text { Grid system with } \\
\text { accessories (chess } \\
\text { system) }\end{array}$ \\
\hline 4 & $\begin{array}{l}\text { It is preferred } \\
\text { to be used in } \\
\text { rural areas } \\
\text { and suburbs }\end{array}$ & Of high cost & $\begin{array}{l}\text { It is used in isolated areas } \\
\text { and the cost of delivering } \\
\text { water from central } \\
\text { processing projects is high }\end{array}$ & $\begin{array}{l}\text { Combined water } \\
\text { services system } \\
\text { (water parks) }\end{array}$ \\
\hline
\end{tabular}




\subsection{The second semester / the practical side/information gathering Drinking water services in the holy city of Najaf}

Where potable water is distributed through a group of projects, complexes and RO stations, as shown as follows (Annual Report2019, 2020):

Number of central operating projects: 8 projects of capacity $(50 \mathrm{~m} 3$ / hour - 11,000 m3 / hour)

* The number of complexes central working is 15 complexes with a capacity (120 m3 / hour - $3000 \mathrm{~m} 3$ / hour)

* The number of rural complexes is 100 complexes of capacity (20 m3 / hour - $400 \mathrm{~m} 3$ / hour)

Number of RO stations: 24 stations (10 m3 / hour - $30 \mathrm{~m} 3$ / hour)

Number of relay stations 1 station (14000 m3 / hour)

\subsubsection{Problems facing drinking water services}

The drinking water delivery service in the holy city of Najaf suffers from several obstacles and problems, including: - The increase in water scarcity as a result of incorrect use of water, in addition to misuse and irregular contributions (Annual Report2019, 2020).

1. The scarcity of water in the river (ie the source) and the disruption it causes to projects and complexes.

2. Lack of continuous electricity for some projects and complexes, which leads to reduced operating hours.

3. Lack of fuel allocated as it is not sufficient to operate generators and machines for longer working hours to cover scarcity.

4. Deposition of mud and suspended materials in the network pipes, in addition to the presence of cracks that work on reverse osmosis when the water is cut off, as if not cleaning it will lead to continuous pollution of the water that reaches the citizen.

5. The lack of awareness of the population towards services leads to wasting water as a result of fluctuating water pressure in the network as a result of the change in the rate of consumption, up or down.

6. The pressure stabilization effect requires additional pumps to operate to balance the grid, and therefore additional costs. 
7. Water service projects have been subjected to many violations and violations by citizens (farmers and plant owners), which led to a high rate of deficit in project performance.

8. Due to the expansion of the city, the positive growth rate of the population increased and the number of arrivals increased, which led to the consumption of large quantities of water that exceeded the project's capacity.

From the foregoing, it can be concluded that the sanitation services system suffers from many problems and deficiencies in its performance, which exposes it to a decrease in quantitative and qualitative efficiency, as the problems that the sanitation services system faces have many and varied causes, including technical, social or economic reasons and must be studied. Understanding and familiarity with it so that we can find appropriate and correct solutions to raise the efficiency of the system's performance and the most important of these reasons are as shown in the following (Table 6):

Table 6. The most important causes of drinking water delivery service problems / Source: The researcher based on the above information.

\begin{tabular}{ccllll}
\hline $\mathrm{v}$ & Paragraphs & reasons & Proportions & Notes \\
\hline 1 & $1-2-2-9$ & Technical reasons & $60 \%$ & $\begin{array}{l}60 \% \text { of the majority of the reasons were } \\
\text { technical reasons resulting from system- } \\
\text { specific factors (operational and design } \\
\text { reasons), in addition to societal factors } \\
\text { represented by the violation of the system, } \\
\text { misuse and failure to maintain the system by } \\
\text { individuals, so we must focus on these reasons } \\
\text { and give priority to them so that we can reach } \\
\text { solutions Integrated }\end{array}$ \\
& $1-6-8$ & Societal reasons & $30 \%$ & $10 \%$ & Economic reasons
\end{tabular}

\subsubsection{Data processing (analysis)}

The researcher has adopted several methods of data processing according to the privacy of the collected and measured vocabulary, as follows: -

1- Descriptive analysis of the study area: by adopting the information obtained from surveys and field interviews, in addition to the charts and images that were taken and available from them and which were analyzed within the concepts presented in the theoretical framework.

2- Mathematical - Statistical Analysis: Analyzing data and obtaining mathematical results using mathematical equations and the Excel program (statistical processor).

Estimated daily per capita consumption rate: The need for each elected house was calculated (by calculating the amount of its consumption of water for drinking, cooking, bathing, etc.). We 
were able to find the estimated value of the need through a questionnaire list (450 liters/person/day) and accordingly, the amount of deficit in the consumption rate was calculated My Agencies (Table 7):

Table 7. The amount of deficit in the rate of daily water consumption / source: the researcher.

\begin{tabular}{|l|l|l|l|l|l|l|}
\hline district & population & $\begin{array}{l}\text { Actual } \\
\text { consumption } \\
\text { per person } \\
\text { (liters / day) }\end{array}$ & $\begin{array}{l}\text { Actual } \\
\text { consumption } \\
\text { of the } \\
\text { neighborhood }\end{array}$ & $\begin{array}{l}\text { Standard } \\
\text { consumption } \\
\text { per capita } \\
\text { (liters / day) }\end{array}$ & $\begin{array}{l}\text { Consumption } \\
\text { according to } \\
\text { the standard } \\
\text { of the } \\
\text { neighborhood }\end{array}$ & $\begin{array}{l}\text { The } \\
\text { amount } \\
\text { of } \\
\text { deficit } \\
\text { )iters / } \\
\text { day }\end{array}$ \\
\hline $\begin{array}{l}\text { Al- } \\
\text { ameer } \\
\text { district }\end{array}$ & 16403 & 450 & 7381350 & 350 & 5741050 & 1640300 \\
\hline $\begin{array}{l}\text { Al- } \\
\text { milad } \\
\text { district }\end{array}$ & 45706 & 450 & 20567700 & 350 & 15997100 & 4570600 \\
\hline
\end{tabular}

Through the above, it is possible to predict the coming years for the rate of daily water consumption by using the equation below, assuming the actual per capita consumption is constant with the continued increase in the population (Table 8).

$$
\mathrm{PO}=\mathrm{P}(1+\mathrm{R}) \mathrm{n}
$$

Table 8. Predicting the rate of daily water consumption / Al-Amir neighborhood / Source: Researcher.

\begin{tabular}{ccccc}
\hline V & years & population & $\begin{array}{c}\text { Actual consumption per person (liters / } \\
\text { day) }\end{array}$ & $\begin{array}{c}\text { Actual consumption of the } \\
\text { neighborhood }\end{array}$ \\
\hline 1 & 2019 & 16403 & 450 & 7381350 \\
2 & 2020 & 16813 & 450 & 7565850 \\
3 & 2025 & 19022 & 450 & 8559900 \\
4 & 2030 & 21521 & 450 & 9684450 \\
5 & 2035 & 24349 & 450 & 10957050 \\
6 & 2040 & 27548 & 450 & 12396600 \\
\hline
\end{tabular}

Expect the average daily water consumption (Almelad district) as shown in the (Table 9): 
Table 9. Predicting the rate of daily water consumption / Milad district / source: the researcher.

\begin{tabular}{ccccc}
\hline V years & population & $\begin{array}{c}\text { Actual } \\
\text { consumption } \\
\text { per person } \\
\text { (liters / day) }\end{array}$ & $\begin{array}{c}\text { Actual } \\
\text { consumption of } \\
\text { the } \\
\text { neighborhood }\end{array}$ \\
\hline 1 & 2019 & 45706 & 450 & 20567700 \\
2 & 2020 & 46848 & 450 & 21081600 \\
3 & 2025 & 53004 & 450 & 23851800 \\
4 & 2030 & 59969 & 450 & 26986050 \\
5 & 2035 & 67849 & 450 & 30532050 \\
6 & 2040 & 76765 & 450 & 34544250 \\
\hline
\end{tabular}

\subsubsection{Testing fairness of distribution using the Gini coefficient and the Lorenz curve}

Al-ameer District/drinking water services

$$
\mathrm{G}=1-1 /\left(10000 \Sigma\left(\mathrm{s} \_\mathrm{i}+\mathrm{s}_{-}(\mathrm{i}-1)\right) \mathrm{w} \_\mathrm{i}\right)=0.18492936
$$

The answer is closer to zero, so there is fairness in the distribution

Al-melad district/drinking water services

$$
\mathrm{G}=1-1 /\left(10000 \Sigma\left(\mathrm{s} \_\mathrm{i}+\mathrm{s} \_(\mathrm{i}-1)\right) \mathrm{w} \_\mathrm{i}\right)=0.333739737
$$

$\checkmark$ The answer is closer to zero, so there is fairness in the distribution

Figure showing the Lorenz curve for drinking water service / Hay Al Ameer and Al Milad.

(Figs. 2 and 3).

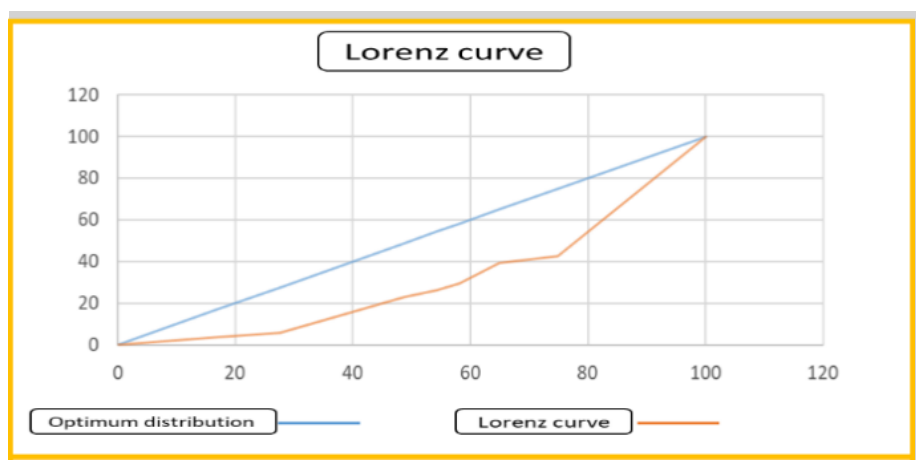

Fig. 2. Lorenz curve for drinking water services / neighborhood of al-milad, source: researcher based on previous data 


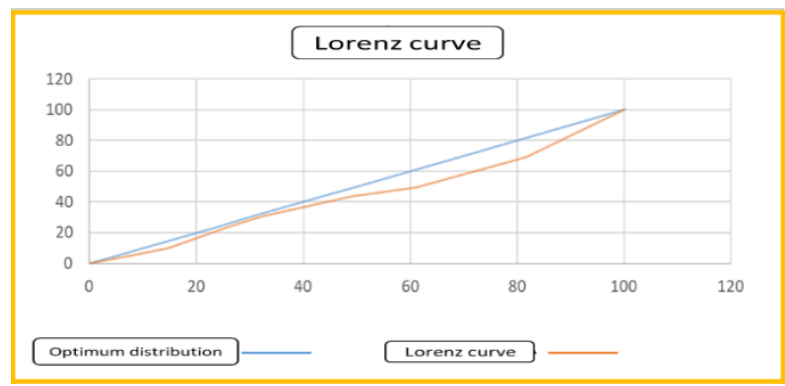

Fig. 3. Lorenz curve for drinking water services / neighborhood of al-ameer, source: researcher based on previous data

\section{BROKEN WINDOWS THEORY TEST AT THE STUDY SITE}

\section{AN EXPERIMENT (NO.1) TO TEST THE BROKEN WINDOWS THEORY IN THE TWO NEIGHBORHOODS}

The experiment was applied to some of the residential homes in the study site for the relevant neighborhoods, and cooperation was made with the cadres of the Al-Najaf Water Directorate. The reason was the answer ((due to the high prices for collection, in addition to the red tape in the departments to complete the task of registration and obtaining the budget, and that the service is bad and does not require payment of wages)). They are given a period of three months until a case is filed and a fine is paid for violating them) and as shown in and the results in the elected districts are as follows: -

1- Al-Amir district

Most of the citizens respond to and accelerate the participation and payment of dues that they owe (response rate $90 \%$ )

\section{2- Al-Milad district}

The response of a small number that does not exceed (10\%) and forcing the concerned department to issue a second and third warning, file a case and force them to pay a fine.

$\checkmark$ Inference/The Amir district's response to the cadres concerned with the application of the rule, to a large extent indicating the district's consciousness and social culture, while we consider the opposite in the district of Al-Milad, which leads us to believe that, in addition to economic and subjective reasons, knowledge and culture have the effect of mitigating and reducing the urban infringement

\section{EXPERIMENT (NO.2) TO TEST THE BROKEN WINDOWS THEORY IN THE TWO DISTRICTS}

The experiment was applied to some of the houses under construction and was cooperated with the cadres of the Al-Najaf Water Directorate, where we noticed some of the houses under 
construction infringing on the main drinking water pipe and making a piece and using it in the construction in addition to the violation of the electric power cable and throwing waste and debris in the manholes Sanitation, where the situation was observed on several floors and when asked about the reason, the answer was ((because of the need for services to complete the construction process, and when asked about the possibility of them being subjected to legal accountability, their answer was that there was no control)), after which the cadres of the Najaf Water Directorate were sought and held accountable Only two roles of the aggressor's role, and the results were as follows: -

\section{1- Al-Amir districts}

We noticed that after the role was held accountable, the rest of the role ceased to infringe and lift the transgression by themselves without the intervention of the cadres of the Directorate of Water of Najaf and when asked about the reason ((the answer was for fear of the fine and accountability and so that it is not an obstacle to cutting work in the role)) and the response rate was $70 \%$

\section{2- Al_Milad district}

We noticed that after the role was held accountable, the rest of the role stopped infringing and lifting the transgression by themselves without the intervention of the cadres of the Najaf Water Directorate, and when asked about the reason ((the answer was for fear of the fine and accountability and even not an obstacle to cutting work in the role)) and the response rate was $30 \%$.

$\checkmark$ Inference /Initially, the infringement was carried out, to assure the citizens that there was no accountability by the concerned authorities, especially after they saw others assaulting without accountability, but after accountability was completed, self-discipline and deterrence of the transgression were done on their own for fear of penalties. We infer that the pattern of societal behaviour makes the application of law and legislation a feature of it in the event of continuous and not interrupted monitoring and accountability.

Inference: From the aforementioned test of the implications of the broken window theory, it was concluded that the theory affects aspects directly, while it affects other aspects in a secondary and indirect way. Safety, stability, belonging and giving a sense of satisfaction to the community, as shown in the (Fig. 4). 


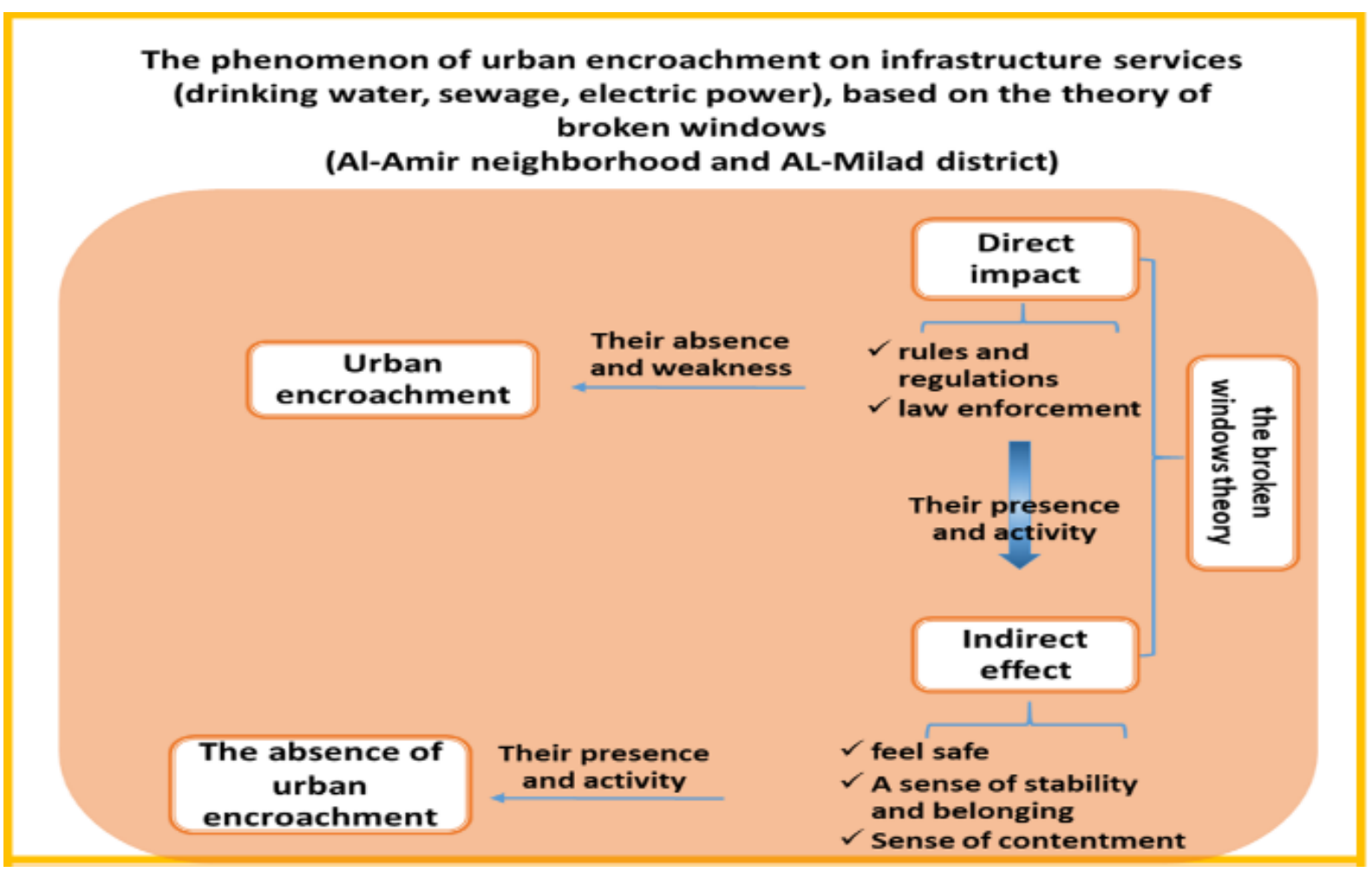

Fig. 4. The phenomenon of urban encroachment on infrastructure services based on the theory of broken windows, source: the researcher based on the experiments at the study site.

\section{THE EFFECT OF EXPERIMENTS IN THE THEORY OF BROKEN WINDOWS ON THE STUDY SITE: -}

It was noted that the theory varies its impact according to the affected factors, so we noticed that it has a very large impact when applied at the level of society, community relations, and the cultural and educational factor, in addition to its moderate influence on the level. To maintain security, stability and law enforcement

And its respect for it by society, while we noticed its weak effect when it was tested for purposes related to awareness, a sense of belonging, stability, and interest in services, the theory is mainly a social, security and legal theory, as shown in the (Table10). 
Table 10. The effect of broken windows theory experiments on the study site / source: the researcher in cooperation with the concerned authorities and official departments.

\begin{tabular}{llllll}
\hline Factors & $\begin{array}{l}\text { The legal and } \\
\text { security } \\
\text { factor }\end{array}$ & $\begin{array}{l}\text { Community } \\
\text { factor }\end{array}$ & $\begin{array}{l}\text { The } \\
\text { economic } \\
\text { factor }\end{array}$ & $\begin{array}{l}\text { The cultural } \\
\text { and educational } \\
\text { factor }\end{array}$ & Self factor \\
\hline $\begin{array}{l}\text { The degree } \\
\text { of impact }\end{array}$ & $* *$ & $* * *$ & $*$ & $* *$ & $*$ \\
\hline$\checkmark$ Note $*$ Weak Effect $* *$ & Medium Effect $* * *$ Strong Impact
\end{tabular}

\section{COMPARISON BETWEEN THE IMPACT OF BROKEN WINDOWS THEORY EXPERIMENTS GLOBALLY AND ON THE STUDY SITE: -}

After studying the implications and impact of the broken window theory internationally, and on the site of the study, differences appeared in the results, as shown in the (Table 11).

Table 11. Comparison between the impact of broken windows theory experiments globally and on the study site / source: the researcher.

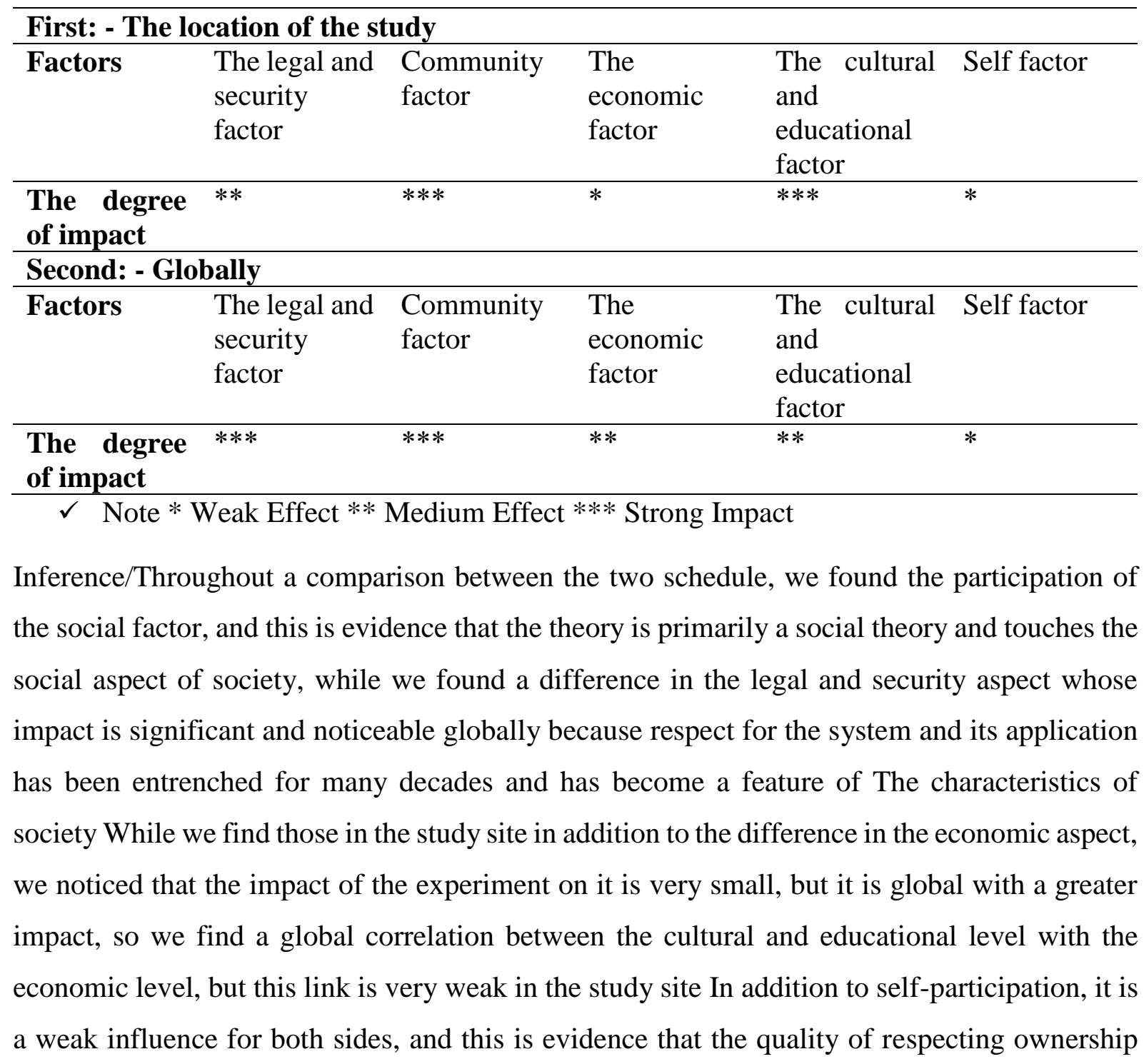


and maintaining the system is a trait acquired through the presence of surrounding and appropriate factors rather than an inherited advantage.

\section{INFERENCES AND RECOMMENDATIONS}

\section{1. inferences}

1- A mistake in the data recorded in the infrastructure services departments (drinking water services) because the presence of some residential plots is divided into more than one residential house, but it is calculated at the concerned role as one piece and this affects the accuracy of calculating the actual need for individuals for infrastructure services.

2- Equity in the distribution of infrastructure services to the city areas

3- Community dissatisfaction with the reality of infrastructure services in terms of efficiency and quantity.

4-The insufficiency of infrastructure services projects compared to the actual needs of the area, and this was inferred by calculating consumption compared to the amount of equipment.

5- Individuals are ready to infringe on infrastructure services in the absence of accountability from the relevant authorities, while the rate of violation decreases when accounting and determining fines.

6-There are no statistically significant differences in the nature of individuals' consumption of infrastructure services, as the average daily consumption of water and energy is close to that of the two districts.

7-Individuals' ignorance of laws and legislations related to the infringement of infrastructure services.

8- Individuals lack a sense of belonging and interest in infrastructure services, and this was observed through their discovery of aggressors and not interfering with reporting or providing advice for fear of the consequences.

9-The absence of serious campaigns to remove the abuse by the competent authorities on infrastructure services.

10- The infrastructure services depend heavily on generators to fill the shortage of electric power as a result of the programmed power outage, and this matter affects the efficiency of the stations 'work as well as the costs of preparing the kerosene necessary for the work. For generators, transportation costs, and generator faults repair costs. 
11-The most important problems of infrastructure services are poor awareness and misuse, in addition to their old efficiency and poor efficiency. Then comes in the second degree the scarcity and volatility of the electrical energy required for its work, and then in the third degree the issue of the poor. Planned periodic maintenance and lack of sustainability, and in the fourth degree the excesses of these services.

12- Not to benefit greatly from the geographic information systems (GIS) program in the process of creating a spatial database for infrastructure services for the process of analysis and service management, which leads to following up the successive development and identifying the most important problems more accurately in all infrastructure services organizations.

13-Most of the problems in infrastructure services systems are technical problems, some of them are operational, design and financial reasons, and the largest part results from infringement and lack of maintenance by individuals in addition to poor consumption and waste.

\subsection{Recommendations: -}

\subsubsection{General recommendations: -}

1-The texts of laws and legislations that keep pace with the development in urban construction and are in line with the reality of the situation.

2-Providing adequate financial funds to operate, develop and invest in infrastructure services.

3-Increasing community awareness of maintaining infrastructure services

4-Reaching the state of satisfaction with the community departments with regard to infrastructure services (satisfaction in terms of efficiency, adequacy, and collection pricing) by raising the service efficiency, in terms of quantity and quality.

5-Providing integrated, organized, adequate, and highly efficient infrastructure services in line with international standards

6-Enhancing the sense of citizenship and community belonging to its urban infrastructure.

7- Providing the necessary protection for infrastructure services

8- Eliminating the phenomenon of urban sprawl is done through an integrated plan and a vision of the most important reasons that led to achieving the desired goals of the plan.

9-The necessity of conducting a field study of the area to be treated in order to identify its human, economic and societal nature in order to reach sound, thoughtful and accurate solutions. 
10- Spreading the spirit of respect for the law and legislations and their proper and correct application

11- Activating the role of individuals' participation in the decision-making process

12-Increase the wages for collecting infrastructure services gradually and imperceptibly, thus reducing the per capita's share of daily consumption of infrastructure services (drinking water services)

13- Paying attention to the periodic maintenance of infrastructure services.

14-Using geographic information systems (GIS) as an effective tool to facilitate the process of studying infrastructure services, diagnosing the most important problems they suffer from, and adopting them as a digital and visual electronic database that leads to their follow-up. For successive development and knowing the extent of pressure on services, which facilitates finding a balance between their job performance and the amount of pressure on it.

\subsubsection{PROPOSED STRATEGIES}

Gaining citizens' satisfaction by improving the provision of effective and sustainable services to all consumers, reliable in quantity and quality, and striving to achieve the highest levels of excellence by continuing to develop the service, optimal planning, enacting the necessary laws, and providing the necessary protection to obtain effective, sustainable and highly efficient infrastructure services to confront the phenomenon of urban encroachment.

Strategic aims (the vision) to processing the phenomenon of infringement of infrastructure services (drinking water)

1-Increasing the design capacity of the central relay station by (5000 $\mathrm{m} 3$ / hour) annually to maintain the efficiency of the station and not to extinguish it by adding strengthening units and adopting modern technologies in this field.

2-Promoting and following up any actual need at the level of production and processing in line with the urban growth of the city through modern technology to increase production efficiency. 3-Training technical personnel to raise their capabilities at the level of monitoring and sustainability of resources and dealing with infringement of infrastructure services (drinking water services).

4-Enhancing the technical and technical equipment necessary to raise the efficiency of the service. 
5-Enhancing and maximizing the financial, economic and resources necessary to develop production and follow up on violations and abuses through consulting projects in the field of infrastructure services (drinking water services).

6-Adopting modern mechanisms and techniques in obtaining service wage lists (collection) while increasing awareness and education in this direction and enhancing the spirit of citizenship so that the population feels that this collection aims to increase the efficiency of infrastructure services (drinking water services).

7- Activating the control and accountability committees for violators on the network in accordance with the laws and legislations in force that are commensurate with the size of the abuse and the purchasing power of its local work through pressure on the local and central legislative bodies.

8- Activating the role of technical and technical institutes and professional preparations that provide intermediate technical personnel to support maintenance, operating, collection and accounting committees.

9- Supporting the contribution and participation of the private sector in investment projects that serve the development of production at the level of quantity and quality.

10- Promote large projects and complete them within short-term plans

11- Paying attention to the educational, cultural and social aspect in combating infringement and concluding legal and administrative agreements with the various supervisory authorities to protect this service.

12- Work according to administrative and technical contexts and policies that are not effectively linked to political and security unrest situations.

13- Adopting alternative energy and working to compensate for the energy shortage with complementary investment projects.

14- Enhancing the operational capacity of the heavy water treatment project in line with the plant's design capacity

15- Developing laws and supporting legislation to limit abuses and maximize the economic resources of the relevant authorities.

16- Eliminate the phenomenon of encroachment before it turns into an uncontrollable problem. 


\section{Strategies to achieve the aims}

Through the foregoing, we recommend adopting planning strategies to reduce the phenomenon of urban sprawl in light of the indicators of broken windows theory (B.W). These strategies can be illustrated in the following paragraphs:

\section{First: Short-term Strategies:}

1- Filling the gap in infrastructure services (drinking water services)

2- Utilizing the existing financial and human resources to improve the reality of infrastructure services.

3- Holding training courses to develop the skills of workers in infrastructure services.

4- Carrying out intensive campaigns by working cadres to raise the infringements on infrastructure services and hold the aggressors accountable.

5- Starting to use modern technologies, mechanisms and techniques to improve the quality and quantity of services.

\section{Second, medium-term strategies:}

1-Providing the necessary funds to develop and improve existing infrastructure services

2-Working to increase the design capacity for infrastructure services to fill the service deficiency

3- Buying modern devices and equipment to increase the efficiency of infrastructure services.

4-Filing lawsuits against the aggressors and infringers of infrastructure services to hold them accountable

5- Increasing the awareness of working cadres and citizens on how to deal with infrastructure services.

6- Holding awareness sessions, distributing educational brochures, and holding awareness seminars for citizens on how to maintain infrastructure services.

\section{Third: Long-term Strategies:}

1-Establishing additional infrastructure services stations and projects (drinking water services).

2-Working to change the reality of Iraqi laws and legislations related to infrastructure services.

3-Appointing trained and skilled cadres at the highest level to carry out the collection process to obtain financial resources 
4-Appointing trained and skilled cadres at the highest level to undertake the maintenance, implementation and operation of infrastructure services.

5-Dealing with the private sector and making the necessary investments in the infrastructure services sector.

6-Providing the necessary security protection cadres to protect infrastructure services.

7-Imposing taxes on infrastructure services in order to benefit from the funds in improving the reality of services and forcing the individual to reduce daily consumption.

\section{REFERENCES}

1. Zimbardo P (1973) A Field Experiment in AutoShaping. In: Ward C (ed) Vandalism, Architectural Press, London.

2. Harcourt B (1998) Reflecting on the subject: A critique of the social influence conception of deterrence, the broken windows theory, and order-maintenance policing New York style. Michigan Law Review 97(2)

3. Mansi, Walid Abdullah Mazher, Urban Encroachment in Kuwait City, Journal of Gulf and Arabian Peninsula Studies, Issue 120, Kuwait, 2007.

4. Al-Falahi, Ahmad Salman Hammadi, Overriding the Basic Design (The City of Fallujah An Applied Study), Anbar University Journal of Human Sciences, Volume III / Issue 14, Anbar University - College of Arts - Geography Department, 2008.

5. The Housing and Building Research Center in cooperation with the Center for Housing and Urban Development Studies in the Netherlands - Training course (Planning and Management of Upgrading Projects in Informal Areas - Cairo, February 2000.

6. Al-Sarafandi, Faraj Mustafa, Strategies for Developing Informal Areas in Gaza Governorates (Case Study - Al-Mughraqa), 2011.

7. Al-Maliki, Nada Qassem Zayed, "Study of Infrastructure and Methods of Treating it," Master's thesis submitted to the Center for Urban and Regional Planning, Baghdad University, 2013.

8. Omar, Muhammad Ismail, Water Treatment, Dar Al-Kutub Al-Ilmiya, Cairo, 2010

9. "Annual Report2019", Maintenance Committee, Engineering Division, Najaf Water Directorate, Ministry of Municipalities and Public Works, Iraq, 2020. 